\title{
Unilateral facial pain and headache: Effects of both indomethacin and sumatriptan
}

\author{
Ottar Sjaastad MD PhD ${ }^{1}$, Torbjörn A Fredriksen MD PhD ${ }^{2}$, Juan A Pareja MD PhD ${ }^{1}$, Andreas Stolt-Nielsen MD ${ }^{2}$.
}

\section{O Sjaastad, TA Fredriksen, JA Pareja, A Stolt-Nielsen. Unilateral facial pain and headache: Effects of both indometha- cin and sumatriptan.}

Pain Res Manage 1999;4(4):179-184.

Three female patients presented with a similar pattern of unilateral facial pain and headache, reminiscent of atypical facial pain. The neck and ipsilateral shoulder $(\mathrm{n}=2)$ were also involved. The attacks of pain lasted from several hours to days. There was some tenderness in the neck, but upper cervical nerve anesthetic blocks did not provide any positive results. Indomethacin, taken at the time of the attacks, exerted a very marked effect. Sumatriptan produced an even more rapid and complete effect, but with intolerable side effects, including malaise and breathing difficulties.

The unilateral facial pain and headache described in these cases resembles both cervicogenic headache $(\mathrm{CEH})$ and hemicrania continua (HC), especially the former, which may be associated with both facial and shoulder pain. Indomethacin is, however, generally not effective in CEH. A clear sumatriptan effect in the cases studied is remarkable because there is usually little or no sumatriptan effect in HC. Atypical facial pain is difficult to treat, and probably does not respond well to indomethacin. The present study found that some patients with a similar symptomatology may benefit from indomethacin. The demonstrated effectiveness of indomethacin or sumatriptan makes it important to recognize such cases. Future serotonin agonists may have a more favourable effect to side effect ratio than sumatriptan and provide a more ideal approach to therapy in such cases.

Key Words: Atypical facial pain; Headache;Indomethacin; Sumatriptan

\section{Douleur au visage et céphalée unilatéral : Effets de l'indométhacine et du sumatriptan}

RÉSUMÉ : Trois patientes se sont présentées avec un tableau similaire de douleur au visage et de céphalée unilatérales, évocateur d'une douleur faciale atypique. Le cou et l'épaule épsilatérale $(n=2)$ étaient aussi touchés. Les crises douloureuses duraient de quelques heures à quelques jours. On notait une sensibilité au cou, mais les blocs cervicaux supérieurs n'ont pas donné de résultats positifs. L'indométhacine administrée au moment des crises a exercé un effet très marqué. Le sumatriptan a produit un effet encore plus rapide et complet, mais s'est accompagné d'effets secondaires intolérables, entre autres, malaises et difficulté respiratoires. Ce type de céphalées ressemble à la céphalée cervicogène et à l'hémicrânie continue, surtout à la première qui est parfois associée à une douleur au visage et à l'épaule. L'indométhacine est par contre en général inefficace dans la céphalée cervicogène. L'effet indéniable du sumatriptan dans les cas étudiés est remarquable, en comparaison de son effet dans l'hémicrânie chronique qui est en général léger, voire nul.

La douleur atypique au visage est difficile à traiter et répond plus ou moins bien en général à l'indométhacine. La présente étude a révélé que des patients présentant une symptomatologie similaire peuvent tirer profit de l'indométhacine. Le potentiel thérapeutique est donc important pour l'identification de tels cas. Les prochains agonistes de la sérotonine pourraient avoir un effet favorable en ce qui a trait au ratio d'effets secondaires, comparativement au sumatriptan et constituer ainsi une approche thérapeutique plus convenable.
$\mathrm{P}$ rotracted, unilateral headache, without change of side, is characteristic of both cervicogenic headache $(\mathrm{CEH})$ in its typical form $(1,2)$ and hemicrania continua (HC) $(3,4)$.
These headaches share other clinical traits, including maximum pain in the oculofrontotemporal area, similar levels of pain intensity, and moderately expressed autonomic signs

Departments of ${ }^{1}$ Neurology and ${ }^{2}$ Department of Neurosurgery, Regionsykehuset i Trondheim, Trondheim University Hospitals, Trondheim, Norway Correspondence and reprints: Dr O Sjaastad, Regionsykehuset I Trondheim, Trondheim University Hospitals, 7006 Trondheim, Norway.

Telephone +47 738671 18, fax +47 738693 13, e-mail berit.mjoen@medisin.ntnu.no

Received for publication January 26, 1999. Accepted July 20, 1999 
TABLE 1

Clinical features of the present patients with unilateral facial pain and headache

\begin{tabular}{lccccc}
\hline Patient & Sex & Age of onset & Duration (years) & $\begin{array}{c}\text { Previous migraine } \\
\text { without aura }\end{array}$ & Familial migraine \\
\hline 1 & Female & 23 & 16 & No & No \\
2 & Female & 36 & 11 & No & No \\
3 & Female & 47 & 7 & Ages 5-45 years* & Yes \\
\hline
\end{tabular}

No temporal relationship to menstruation was found in any of the patients. ${ }^{*}$ The new headache started 1.75 years after the migraine attacks had completely disappeared

TABLE 2

Characteristics of the attacks

\begin{tabular}{|c|c|c|c|c|c|c|c|c|c|}
\hline Patient & $\begin{array}{c}\text { Unilaterality } \\
\text { of pain }\end{array}$ & Nausea & Vomiting & Photophobia & Phonophobia & $\begin{array}{c}\text { Pulsatile pain } \\
\text { quality }\end{array}$ & $\begin{array}{c}\text { Attack } \\
\text { duration }\end{array}$ & $\begin{array}{c}\text { Attack } \\
\text { frequency } \\
\text { (mean) }\end{array}$ & $\begin{array}{c}\text { Maximal } \\
\text { severity } \\
\text { (Scale 0-5) }\end{array}$ \\
\hline 1 & Left & Rarely & No & Rarely (ss) & No & Yes* & $4-8 \mathrm{~h}(-24 \mathrm{~h})$ & 1 per day & 4 \\
\hline 2 & Right & Rarely & $\begin{array}{l}2-3 \text { times } \\
\text { per year }\end{array}$ & No & No & No & 1-6 days & $\begin{array}{l}2-3 \text { per } \\
\text { month }\end{array}$ & 4 \\
\hline 3 & Right & No & No & No & No & Very rarely & 3-4 days & 1 per week & $3(4)$ \\
\hline
\end{tabular}

Localized autonomic phenomena such as lacrimation, nasal secretion, conjunctival injection on the symptomatic side were not present except for modest, occasional lacrimation in patient $1 .{ }^{*}$ Throbbing with involvement of the temporal region during severe pain attacks. ss Symptomatic side.

TABLE 3

Pain in other areas of the body on the symptomatic side in connection with attacks

\begin{tabular}{lccc}
\hline Patient & Neck & Shoulder & Upper arm \\
\hline 1 & Yes & No & No \\
2 & Yes & Very rarely & No \\
3 & Yes* & Yes* & Yes* \\
\hline
\end{tabular}

*Pain in this area delayed by a couple of hours as compared to the initial pain in the frontotemporal area.

and symptoms. The majority of patients who consulted headache specialists about both categories of headaches were women. The differences, however, seem to be more marked than the similarities.

Indomethacin has an absolute and lasting effect in $\mathrm{HC}$ but only minimal effectiveness in CEH. Attacks of CEH $(1,2)$, but not those of $\mathrm{HC}$ (3), may be precipitated mechanically. Furthermore, the effect of upper cervical local anesthetic blockades is widely different in CEH (5) and HC (6).

Three patients with unilateral headache with similarities to $\mathrm{CEH}$ but also sufficiently resembling $\mathrm{HC}$ in its nonchronic form to justify a trial of indomethacin are discussed. At a later stage, sumatriptan was also tried. It should be emphasized that in these cases, not only was the headache combined with facial pain, also occasionally the facial pain seemed to dominate.

\section{CASE PRESENTATIONS}

The study group consisted of three young to middle-aged, female patients with similar case histories, outlined in Tables 1,2 and 3.

\section{Case 1}

A woman born in 1960 had recurring, left-sided upper lip, herpes-like exanthemata for about 10 years before the onset of left-sided headache and facial pain at the age of 23 years (Table 1). Initially, facial pain and headaches appeared annually, in approximately one-half-year periods (spring and summer). During symptomatic periods, alcohol led to attacks. At age 30 years, there were a few days per month that were free of headaches. Mild combination analgesics became ineffective over time, and the patient eventually had to stop working. However, during pregnancy and breastfeeding, between ages 34 and 35 years, the attacks were reduced to approximately three per month.

Low intensity pain persisted between solitary attacks that lasted 4 to $8 \mathrm{~h}$. Occasionally, there was more than one attack per day, the attacks were usually oligosymptomatic (Table 2). Sometimes there was mild neck tenderness (Table 4). Pain started in the cheek, approximately midway between the angle of the mouth and the temporomandibular joint (TMJ) (Figure 1) and afterwards involved the ocular and nasal area, the angle of the mandible and the nape of the neck (Table 3). If, in the course of this process, the temporal area became involved, a severe attack would develop with throbbing. During the years before surgical interventions, combing hair posteriorly on the symptomatic side was unpleasant.

There was suspicion of atypical trigeminal neuralgia (branches II-III) but several courses of carbamazepine (600 $\mathrm{mg}$ /day) were ineffective. A Jannetta operation (7) was done when the patient was 28 years of age. Surgery was performed on a small artery and vein impinging on the trigeminal root; however, after a few days the attacks recurred. Dorsal column electrical stimulation (8) with positioning of the electrode just superior to the spinous process of the second cervical verte- 
TABLE 4

Local tenderness in the neck and head on the symptomatic side of the present patients with unilateral facial pain and headache

\begin{tabular}{lccccc}
\hline Patient & Temporal area & Supraorbital nerve & $\begin{array}{c}\text { Upper part } \\
\text { sternocleidomastoid } \\
\text { muscle }\end{array}$ & $\begin{array}{c}\text { Trapezius } \\
\text { tendons }\end{array}$ & $\begin{array}{c}\text { Groove behind } \\
\text { mastoid process }\end{array}$ \\
\hline 1 & Rarely & No & No & Rarely & Rarely \\
2 & Yes & No & Yes & Yes & Yes \\
3 & Rarely & Yes & Yes & Yes & Rarely* \\
\hline
\end{tabular}

There was no particular tenderness over the infraorbital nerve; local tenderness generally seemed more marked during than between attacks. *Slight irradiation towards temporal area

bra was tried at age 29 years. There was some improvement that lasted only a few days. Glycerol injection into the cavum Meckeli (9) at age 30 years was effective for a few days only. A TMJ disorder was suspected, but the patient was never treated for this disorder.

At the age of 32 years, indomethacin was tried prophylactically, starting with daily doses of up to $275 \mathrm{mg}$; this appeared to have a moderate effect on the duration of the attacks (mean $2.7 \mathrm{~h}$, range 2 to $3.5 \mathrm{~h}$, Table 2). However, at this high dose the patient developed annoying bilateral headache. Through trial and error, another regimen was developed; indomethacin suppositories $(50 \mathrm{mg})$ at the onset of the attacks resulted in significant alleviation of the pain (residual pain $0 \%$ to $20 \%$, within 1 to $2 \mathrm{~h}$, mean $1.7 \mathrm{~h}$ ). This dose regimen was clearly superior to a high total dose, spread evenly over $24 \mathrm{~h}$.

Sumatriptan had a complete effect within 30 mins and was effective for more than $3 \mathrm{~h}$. Unfortunately unpleasant side effects persisted for about $1 \mathrm{~h}$ (Table 5).

\section{Case 2}

A woman born in 1952 had attacks of right-sided headache and facial pain starting in 1988. The episodes lasted one to two days and appeared bimonthly. Later, pain episodes lasted longer (five to six days), and pain was present during one-third to one-half of the days (Table 2). Between attacks, there was no pain. A solitary attack generally started in the cheek, just anterior to the ear. It spread from there, occasionally involving the right shoulder (Figure 1, Table 3). Long lasting, severe attacks led to some contralateral vertex discomfort. Mild combination analgesics alleviated the pain initially. Over the years, there was an increase in the severity of the pain. During the worst episodes, the patient stayed in bed, occasionally even attempting to stand on her head.

Increased tenderness corresponding to the groove behind the mastoid process and the area just in front of the TMJ on the symptomatic side was demonstrated (Table 4).

Suspicion regarding the source of pain had been directed toward an upper jaw tooth that was ultimately declared harmless and the TMJ on the symptomatic side (Table 6), but dental appliances worn for two months were not effective.

Prophylactic treatment with indomethacin (150 mg daily) was associated with bilateral headache, approximately at the same level of magnitude as the previous unilateral one. A new trial using smaller doses (Table 5) centred on the solitary

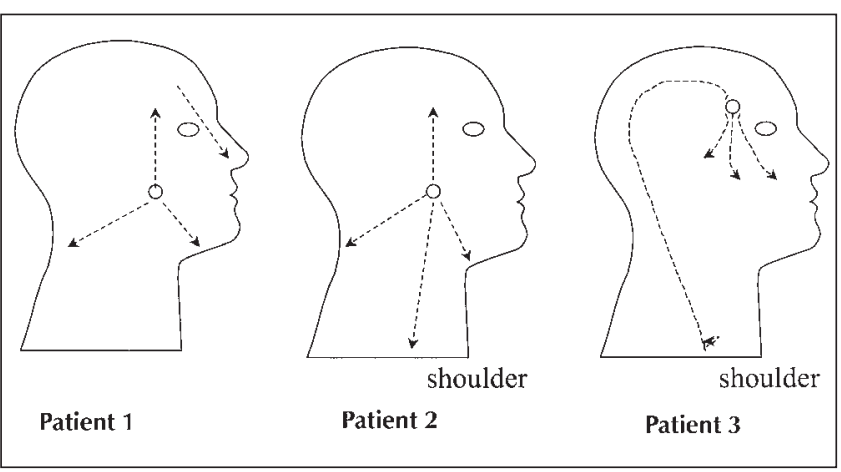

Figure 1) Schematic presentation of the pain in all three cases. The pain was left-sided in patient 1, but to ease comprehension it is depicted as though it were right-sided

attacks and was adjusted according to pain intensity. This trial resulted in improvement depending on how quickly and efficiently therapy could be initiated; usually there was no recurrence of pain. More recently, either untreated attacks or attacks treated only with paracetamol $(500 \mathrm{mg}$, three times per day), ended up as close to $100 \%$ attacks, with nausea and vomiting within one to two days. In such attacks, indomethacin provided relief within a couple of hours. Injection of indomethacin ( $50 \mathrm{mg}, \mathrm{n}=2$ ) was effective within $1.75 \mathrm{~h}$ to $3 \mathrm{~h}$ but provided no advantages over taking the medication orally.

Sumatriptan alleviated the pain within 20 mins $(n=2)$, and the patient was pain-free for approximately $5 \mathrm{~h}$. However, the side effects that began within a few minutes (Table 5) were so marked that the patient refused further doses of sumatriptan, although the beneficial effects seemed to be superior to those of indomethacin. Parenteral ergotamine also relieved the pain (Table 5). Combined greater occipital, minor occipital and auriculotemporal nerve blocks relieved much of the pain in the anesthetized area but were clearly less effective than indomethacin. A third occipital nerve block was ineffective.

\section{Case 3}

A woman born in 1945 had typical migraine attacks without aura beginning at age five years, with side-shift of pain, nausea, vomiting, diarrhea, photo- and phonophobia, and a pulsating headache located in the frontal area that was accentuated by minor physical activity (10). Attacks appeared two to three times per month, lasted about one day, and regularly led to bed rest. Ergotamine suppositories stopped the attacks. 
TABLE 5

Drug treatment perspectives for the present patients with unilateral facial pain and headache

Patient

Drug

1

2

3

Indomethacin (dose)

Degree of pre-existing pain

$50 \mathrm{mg}$ rectally

75-100

25-50 mg orally

20-90

50 mg orally or rectally

(percentage of maximum)

Effectiveness (scale 0 to 3 )

2 (80\% to $100 \%)$

60-90

$2.5(90 \%$ to $95 \%)$

Interval between dose and

effect (mins)

Side effects (scale 0 to 3 )

Sumatriptan (dose)

Degree of pre-existing pain

(percentage of maximum)

Effectiveness (scale 0 to 3 )

Interval between dose and

effect (mins)

Side effects (scale 0 to 3 )

Ergotamine (dose)

Effectiveness (scale 0 to 3 )

Interval between dose and effect

Side effects (scale 0 to 3 )
0

100 mg orally

45-60

$3(n=2)$

30

3*

1 mg orally

$1(n=2)$

no information

0
120-210

0

$6 \mathrm{mg}$ im

45-60

$3(\mathrm{n}=2)$

15-20

3*

$0.5 \mathrm{mg} \mathrm{sc}$

$2.5(n=2)$

$0.75 \mathrm{~h}$

2.5
50-100

$2.5-3$ (90\% to $100 \%)$

30-45

0

$6 \mathrm{mg}$ im

50-60

$3(n=2)$

15

$2^{+}$

$0.5 \mathrm{mg} \mathrm{sc}$

$1.5(n=2)^{\ddagger}$

$1.5 \mathrm{~h}$

$2^{\S}$

Piroxicam, $20 \mathrm{mg}$ orally, was ineffective in patients 2 and 3 and so was naproxen in patient 3. Carbamazepine was ineffective in patient 1 . ${ }^{*}$ Marked malaise and pressure in the chest/neck/throat (patient 1 also had tingling neck, shoulder, and upper arm, symptomatic side), breathing difficulties, and inability to function for $1 \mathrm{~h}$,

${ }^{+}$Marked diffuse discomfort generally in the body of 30 mins duration, ${ }^{\neq}$Ergotamine exerted a positive effect during previous migraine attacks, ${ }^{\$}$ Nausea and marked generalized discomfort. im Intramuscular; sc Subcutaneous

This type of migraine attack continued until the age of 45 years, then stopped completely. Her mother, sister and son experienced migraines. The patient's early attacks, fulfilled both the International Headache Society criteria for migraine (11) and the additional criteria set forth by the authors (10).

Approximately 1.75 years later the patient began having right-sided, oligosymptomatic attacks that started in the frontotemporal area and spread over a couple of hours to other areas, even diffusely into the upper arm (Figure 1, Table 3). Headaches appeared every other day and frequently led to bed rest. Attacks could not be precipitated mechanically. She felt that each 'new' headache was different from the 'old' one. There was clear palpation tenderness in the neck (Table 4).

During the solitary attacks, indomethacin was effective, with no recurrence of pain. Sumatriptan was effective but had uncomfortable side effects. Greater occipital, minor occipital and third occipital nerve blocks were ineffective.

Supplementary tests: For all patients magnetic resonance scans of the brain and cervical spine were within normal limits, except for questionable, slight, degenerative disc signals in the cervical spine $\left(\mathrm{C}_{2} / \mathrm{C}_{3} ; \mathrm{C}_{3} / \mathrm{C}_{4} ; \mathrm{C}_{6} / \mathrm{C}_{7}\right)$ of patient 2 . X-ray of the TMJ showed a slight bilateral malocclusion in patient number 2, which was worse on the nonsymptomatic side. Forehead sweating measured with an evaporimeter $(12,13)$ showed symmetrical levels at rest and after increase of body temperature. Range of motion in the neck was restricted only for rotation in patient number 3 (toward the symptomatic side $74^{\circ}$, toward the nonsymptomatic side $80^{\circ}$, a total of $154^{\circ}$; control levels: mean $\left.\pm \mathrm{SD}, 170^{\circ} \pm 22.1\right)(14)$.

TABLE 6

Putative dental/temporomandibular joint factors in patients with unilateral facial pain and headache

\begin{tabular}{lccc}
\hline Patient number & Dental complaints & Crepitation TMJ (symptomatic side) & Tenderness TMJ (symptomatic side) \\
\hline 1 & No & No & Yes \\
2 & At age 41 upper jaw (ss) & Sometimes & Yes* \\
3 & At age 44 upper jaw (as) + & Sometimes & Rarely* \\
\hline
\end{tabular}

Patient 2 and 3 derived no beneficial effect from dental appliances. None of the patients had bruxism. ${ }^{*}$ Tenderness mainly in front of the joint; ${ }^{+}$No headache sequels after this episode. as Asymptomatic; ss Symptomatic; TMJ Temporomandibular joint 


\section{DISCUSSION}

\section{Head and face pain}

The three patients had rather stereotyped case histories of unilateral pain without sideshift. All were White women; the authors are unsure whether this is a significant factor. At its worst, in two patients, pain tended to spread to the opposite side in the vertex area. There was no tendency towards predominance of pain on the opposite side, nor did there seem to be any clear tendency toward increasing coinvolvement of the opposite side over time; however, the period of observation was limited. There was combined facial and head pain extending to the neck and shoulder $(\mathrm{n}=2)$ or diffusely into the upper arm $(n=1)$ (Table 3). The pain began in the temporal area (patient 3 ) or in front of the ear. However, the spreading of the pain to the temporal area was a predictor for the development of a severe attacks. When fully developed, the pain of the attack was quite marked in the temporal area. In patients 1 and 3, the pain extended to the nasal area, and in patients 1 and 2, it spread to the angle of the jaw. Dental appliances were ineffective $(n=2)$ whatever such a trial is worth in verifying or rejecting a diagnosis of a TMJ disorder.

The attacks were generally severe, appeared at varying intervals, and lasted for hours or several days. There were few localized autonomic phenomena. Between the attacks, there were periods where the patients were free of pain $(n=2)$ or periods of minor headache.

\section{The indomethacin effect}

The indomethacin effect was almost absolute. Were it not for the powers of observation of the first two patients, the positive influence of indomethacin might have been overlooked. A prophylactic dose increase beyond the therapeutically optimal level led to a bilateral vertex headache that seemed to differ from the original headache. This side effect was so annoying that the patients, at one stage, preferred having the original headache to the bilateral vertex headache. To complicate the matter further, a slight involvement of the opposite side of the head might occur during the most severe attacks in the absence of indomethacin medication. Remarkably, a regimen that lowered the dose of indomethacin, aimed at the solitary headache attack proved to be superior to continuous medication. The headache associated with a high dose of indomethacin was probably caused by indomethacin (15).

The interval between oral or rectal indomethacin dose and onset of effect was relatively short, that is 30 to $210 \mathrm{mins}$ (mean 90 to 95 mins) (Table 5). This is approximately the same onset period as in $\mathrm{HC}$, thus leading to only a short period of suffering. With the relatively long remissions seen in patients 2 and 3 (Table 2), intermittent dosing of indomethacin is preferred because this is not a drug that should be given during asymptomatic periods. Although indomethacin markedly ameliorated the pain, it is hardly the ideal drug, because it seems to cause headache at relatively low doses in these patients.

The multiplicity of ineffective treatments that these patients had tried previously and the durable effect of indometha- cin (seven, seven and five years, respectively, without analgesics) attest to the veracity of the indomethacin effect. An indomethacin placebo study was also carried out on patient 2 during two severe attacks of headache and facial pain. The placebo had no effect which is considered a conclusive result.

Another striking feature was the coexistence of an indomethacin and a sumatriptan response, a combination found neither in chronic paroxysmal hemicrania $(16,17)$ nor in the HC cases tested (17), nor generally in CEH (author's observations). The side effects of sumatriptan were, however, remarkable.

\section{CONCLUSIONS}

In early descriptions of atypical facial pain (18), facial pain was combined with head pain. This combination was also present in the patients in our study. There were similarities between the cases in this study and cases of patients with $\mathrm{HC}$ $(3,4)$. There were also similarities between our study patients and those with CEH (4), where shoulder, arm (19) and facial pain (20) were reported. While the locational similarities with regard to CEH are appreciable, the therapeutic aspects seem to differ. Notwithstanding the small size of our study, it appears that indomethacin may be a therapeutic alternative in some patients (maybe women) with traits of atypical facial neuralgia.

The positive sumatriptan response holds promise for the future. It is possible that already the next generation of serotonin agonists, perhaps less prone to side effects, may solve the therapeutic problems in some such headaches. This would be particularly important in patients with upper gastrointestinal side effects from indomethacin.

The consequences of not recognizing such patients with atypical facial neuralgia may be serious. Our first study patient underwent major surgery, a posterior fossa operation, due to the symptomatology of this headache. These patients should be treated conservatively. Reputedly, these headaches may occasionally be due to mid or lower cervical pathology (20).

The message at this stage, therefore, is that in atypical facial pain, the clinician should search for occasional cases exhibiting an indomethacin response of a complete or near complete nature. The second message is that, in some cases, forthcoming serotonin agonists may afford an optimal or close to optimal treatment option.

\section{REFERENCES}

1. Sjaastad O, Saunte C, Hovdal H, et al. Cervicogenic headache. An hypothesis. Cephalalgia 1983;3:249-56.

2. Sjaastad O, Fredriksen TA, Pfaffenrath V. Cervicogenic headache: diagnostic criteria. Headache 1990;30:725-6.

3. Sjaastad O, Spierings EHL. Hemicrania continua. Another headache with absolute indomethacin response. Cephalalgia 1984;4:65-70.

4. Merskey H, Bogduk N. Classification of chronic pain. Seattle: IASP press, 1994.

5. Bovim G, Berg R, Dale LG. Cervicogenic headache: anaesthetic blockades of cervical nerves (C2-C5) and facet joint /C2-C3). Pain 1992;49:315-20.

6. Antonaci F, Pareja JA, Caminero AB, Sjaastad O. Chronic paroxysmal hemicrania and hemicrania continua: anaesthetic blockades of pericranial nerves. Funct Neurol 1997;12:11-5. 
7. Jannetta PJ. Microvascular decompression of the trigeminal nerve root entry zone. In: Rove RL, Murali R, Jannetta PJ, eds. Trigeminal Neuralgia. Baltimore: Williams \& Wilkins, 1990:201-22.

8. Meyerson B, Linderoth B, Lind G. Ryggmärgsstimulering vid kronisk neuropatisk smärta. Läkartidningen 1991;88:727-32.

9. Håkanson S. Trigeminal neuralgia treated by the injection of glycerol into the trigeminal cistern. Neurosurgery 1981;9:638-46.

10. Sjaastad O, Stovner LJ. The IHS classification for common migraine. Is it ideal? Headache 1993;33:372-5.

11. International Headache Society. Headache classification committee. Cephalalgia 1988;8(Supp1 7):1-96.

12. Nilsson GE. On the measurement of evaporative water loss. Linköping University Medical. Dissertation Number 48. Linköping, Sweden, 1977.

13. Saunte C, Russell D, Sjaastad O. Cluster headache: On the mechanism behind attack-related sweating. Cephalalgia 1983;3:175-85.
14. Zwart JA. Neck mobility in different headache disorders. Headache 1997;37:6-11.

15. Gillies HC, Rogers HJ, Spector RG, Trounce JR. A Textbook of Clinical Pharmacology. 2nd edn. London: Edward Arnold, 1986.

16. Dahløf C. Subcutaneous sumatriptan does not abort attacks of chronic paroxysmal hemicrania (CPH). Headache 1993;33:201-2.

17. Antonaci F, Pareja JA, Caminero AB, Sjaastad O. Chronic paroxysmal hemicrania and hemicrania continua: Lack of efficacy of sumatriptan. Headache 1998;38:197-200.

18. Glaser MA. Atypical facial neuralgia: diagnosis, cause and treatment. Arch Intern Med 1940;63:340-67.

19. Jansen J, Markakis E, Rama B, Hildebrandt J. Hemicranial attacks or permanent hemicrania - a sequel of upper cervical root compression. Cephalalgia 1989;9:123-30.

20. Sjaastad O. Headache and the influence of stress. A personal view. Ann Clin Res 1987;19:122-8. 


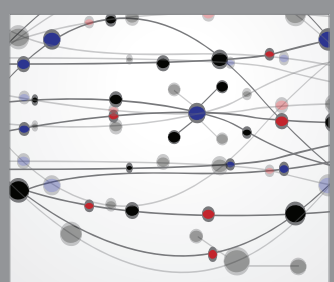

The Scientific World Journal
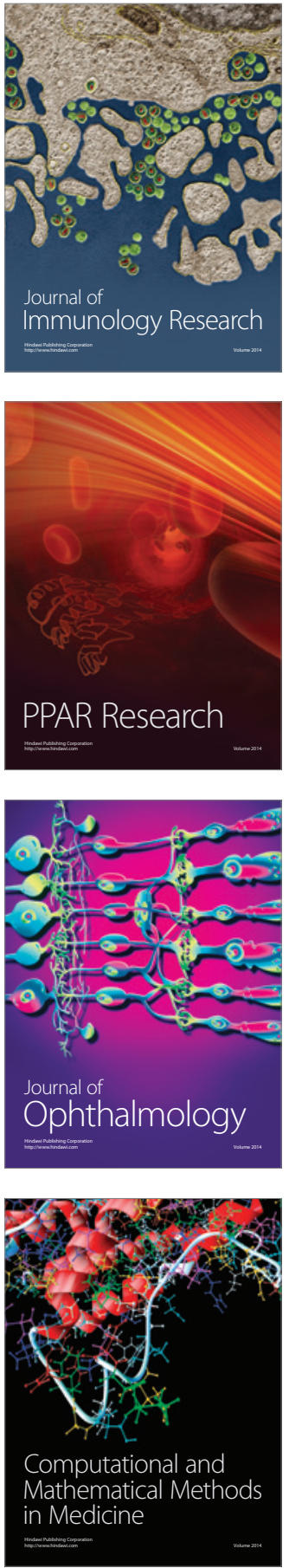

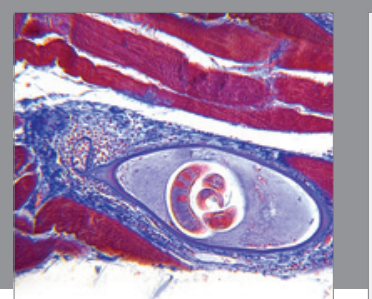

Gastroenterology Research and Practice

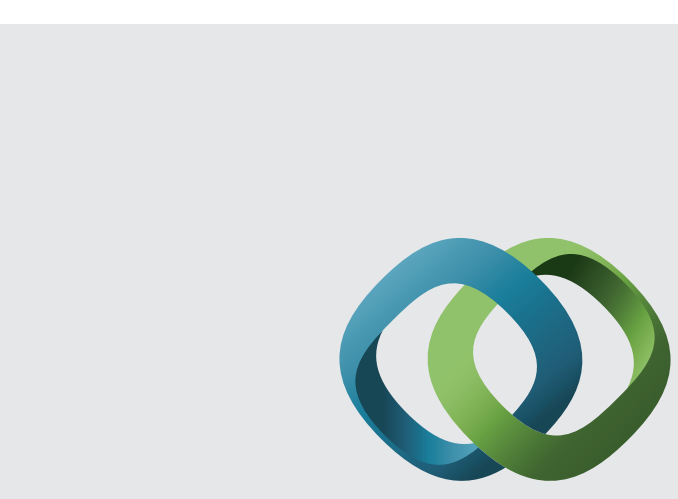

\section{Hindawi}

Submit your manuscripts at

http://www.hindawi.com
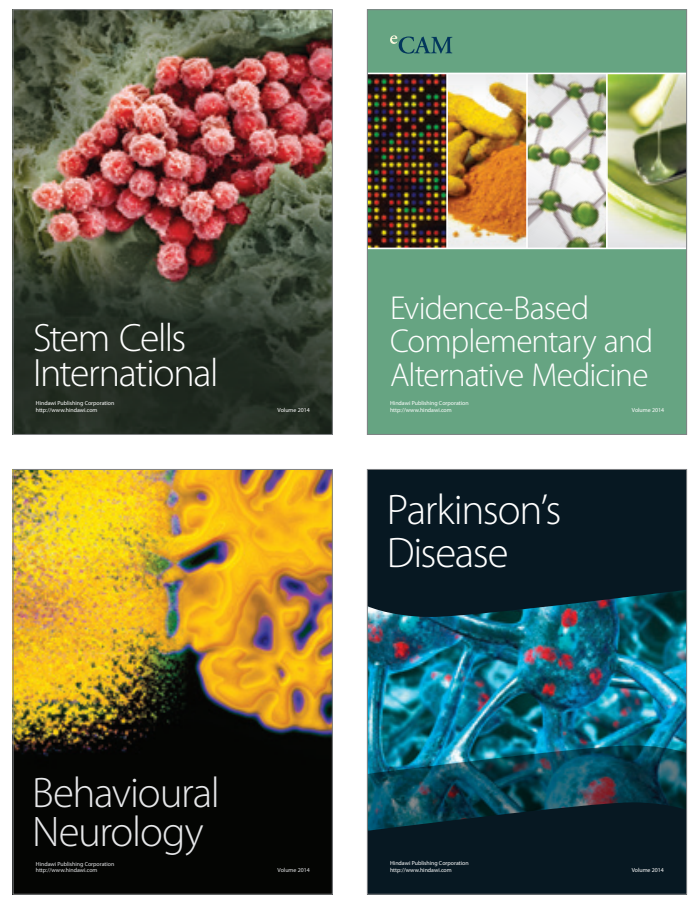
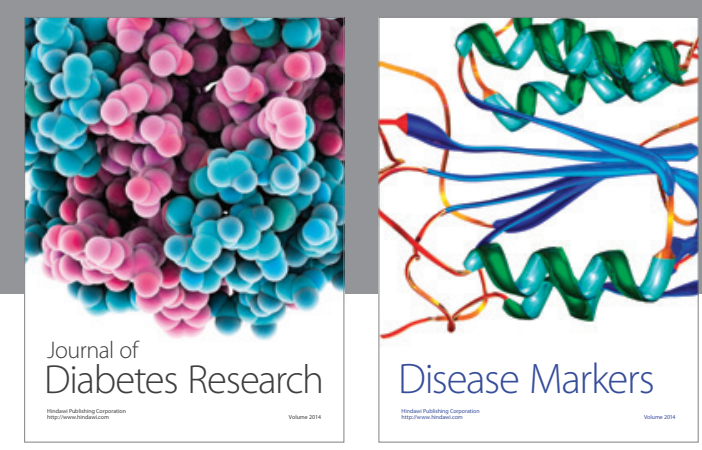

Disease Markers
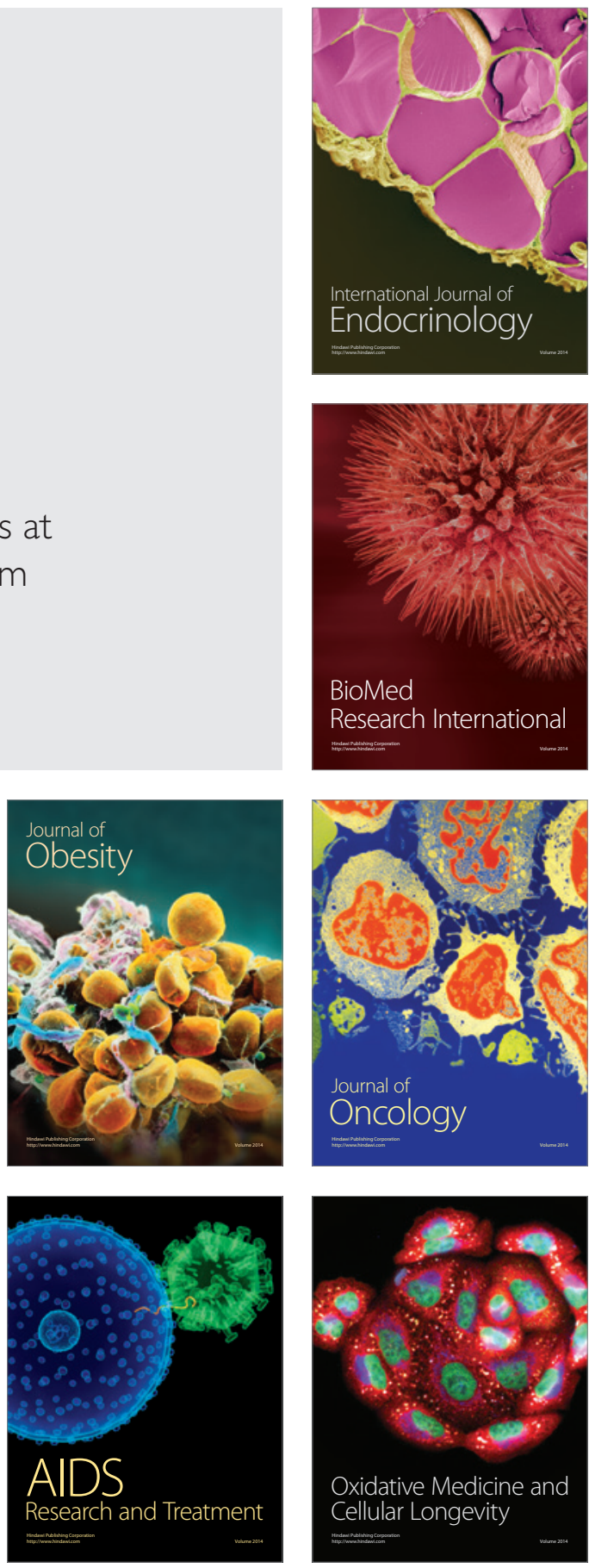